\title{
Introduction to the Donald G. Miller Memorial Tribute
}

\author{
Joseph A. Rard · John G. Albright
}

Published online: 23 January 2014

(C) Springer Science+Business Media New York 2014

Dr. Donald G. Miller passed away on 3 February 2012 at the age of 84. Don will be familiar to many readers of this journal because of his extensive contributions to the field of solution chemistry over about 60 years, particularly in the areas of equilibrium thermodynamics and the thermodynamics of non-equilibrium processes in the linear gradient region and, in recent years, especially the determination and analysis of mass diffusion coefficients in liquid multicomponent solutions including protein-salt-water systems relevant to protein crystallization. Less well known is Don's role as an advocate for a separate journal for solution chemistry that led to the founding of this journal in 1972 with Prof. Robert L. Kay as founding editor.

Although Don's scientific contributions are predominately in solution chemistry, his early research included Boolean algebra, the thermodynamics of rubber, equations of state of gases and the spectroscopy of rare earth ions, and his later research also included analysis of ballistics data and rifling twist, with some contributions to the history of science. It is not our intention to give a complete list of his scientific contributions, which we summarized on the occasion of Don's 80th birthday [1]. Much information about, and many references for, Don's work in diffusion can be found in a historical review of the use of optical interferometry for precision measurements of diffusion coefficients [2]. Additional information about Don Miller and his scientific career can be found on a website created by his grandson Lucio Franco [3].

We are fortunate to have collaborated in scientific research with Don Miller for about 35 years (JAR) and about 40 years (JGA), respectively. Don also collaborated with many other scientists, especially those affiliated with the diffusion research facility at the Università degli Studi di Naploi-Federico II (Italy). We are grateful to two scientists from this

\footnotetext{
J. A. Rard ( $\bowtie)$

4363 Claremont Way, Livermore, CA 94550, USA

e-mail: solution_chemistry2@comcast.net

J. G. Albright

Chemistry Department, Texas Christian University, Ft. Worth, TX 76129, USA

e-mail: j.albright@tcu.edu
} 
university, Prof. Luigi (Gino) Paduano and Prof. Roberto Sartorio, for suggesting this special issue, organizing it, and serving as Guest Editors.

Because much of Don Miller's research since the 1960s was devoted to the experimental determination, analysis and interpretation of diffusion in multicomponent liquid solutions, many of the papers contributed to this issue involve diffusion. The driving (pseudo-) force for mass diffusion in liquid solutions is the gradient of the Gibbs energy (chemical potential gradient), which in turn depends on the natural logarithm of the mean activity coefficients of the solutes, and two papers in the issue involve activity coefficients. There is also a paper on the number of solvent molecules transported by anions and cations in a mixed solvent and another reporting the transference numbers of all anions and cations in the $\mathrm{NaCl}+\mathrm{MgCl}_{2}+\mathrm{H}_{2} \mathrm{O}$ system. This latter paper is the last of a series of papers from an extensive international collaboration involving many laboratories that reported experimental values of the various transport properties, and associated thermodynamic properties, of the $\mathrm{NaCl}+\mathrm{MgCl}_{2}+\mathrm{H}_{2} \mathrm{O}$ system at $298.15 \mathrm{~K}$ that are needed for the calculation of various types of generalized transport coefficients of irreversible thermodynamics. Don Miller was a major organizer and the coordinator of this international collaboration.

The papers in this Memorial Tribute include several by Don's colleagues and by other scientists whose research were influenced by his publications, including many who sought advice from him regarding their research. To include as many papers of these types as possible, two papers are also included that fall outside the usual scope of our journal but which can be considered as offshoots of Don Miller's research.

The first paper is the English version of a lecture presented by Don Miller (in Italian) in 1999 at a symposium honoring Prof. Vincenzo on the occasion of his 70th birthday. Although this lecture was later included in a longer paper with more emphasis on the extensive studies of diffusion in Naples [2], because of the limited distribution of that journal they have given us permission to publish his original lecture. This paper is unchanged except for minor changes needed to conform to the style requirements of the Journal of Solution Chemistry.

Two photographs of Don with other scientists are included that were taken in 1999 (Fig. 1) and 1992 (Fig. 2). The third photograph (Fig. 3) is a more recent picture of Don that was supplied by his wife Miriam (Cohen) Miller.

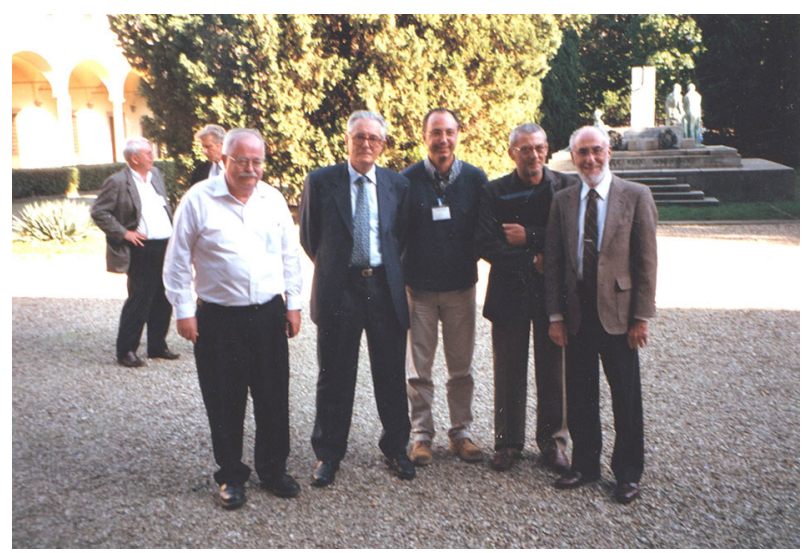

Fig. 1 Photograph taken in Italy in 1999 at the XXth meeting of the Italian Association of Physical Chemistry in Florence. Left-to-right: John G. Albright, Vicenzo Vitagliano, Luigi Paduano (guest editor), Roberto Sartotio (guest editor), and Donald G. Miller. This photograph was supplied by Luigi Paduano 


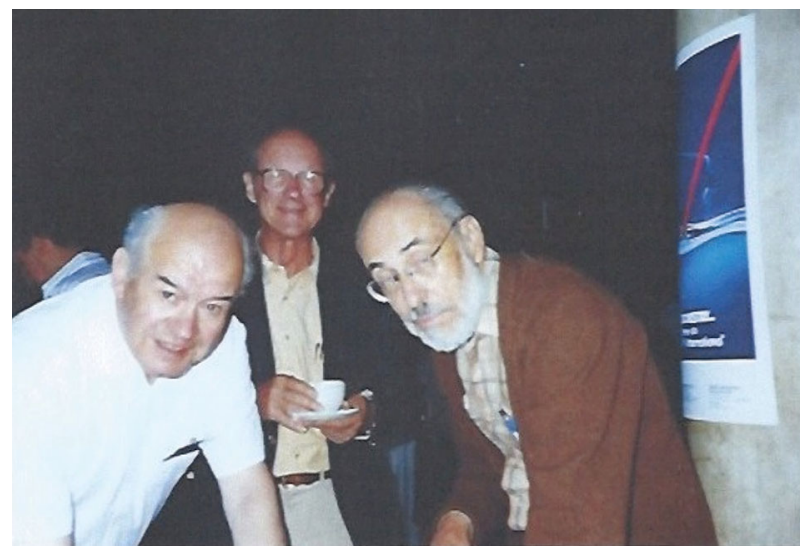

Fig. 2 Left-to-right Josef M. G. Barthel, Robert A. Alberty, and Donald G. Miller. This photograph was taken by Joseph A. Rard at the joint meeting of the 12th IUPAC Conference on Chemical Thermodynamics and the 47th Calorimetry Conference, August 1992, held in Snowbird, Utah

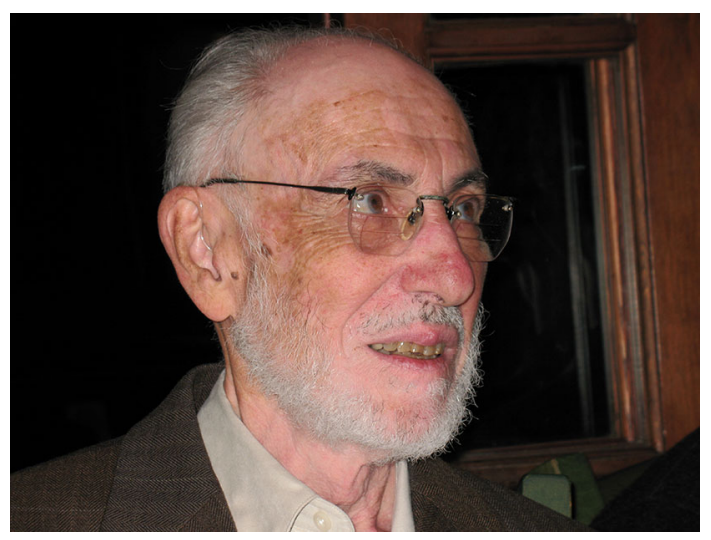

Fig. 3 More recent photograph of Donald G. Miller supplied by Miriam (Cohen) Miller

\section{References}

1. Rard, J.A., Albright, J.G.: Congratulations to Dr. Donald G. Miller on his 80th birthday. J. Solution Chem. 36, 1331-1333 (2007)

2. Vitagliano, V., Costantino, L., D’Errico, G., Ortona, O., Paduano, L., Sartorio, R., Vergara, A., Miller, D.G., Albright, J.G., Annunziata, O.: The history of interferometry for measuring diffusion coefficients. The contribution of Neapolitan group to the study of mutual diffusion. Rend. Acc. Sc. Fis. Mat. Napoli (Accademia delle Scienze Fisiche e Matematich) 74, 191-268 (2007)

3. Franco, L.: http://www.donaldgmiller.com 